\title{
Antropofagia sígnica en el discurso poético de David Añiñir
}

\author{
Signic anthropophagic in the poetic discourse of David Añiñir
}

\author{
Claudio Maldonado Rivera \\ Universidad Católica de Temuco, Observatorio Educacional. \\ Correo electrónico: cmaldonado@proyectos.uct.cl
}

El presente trabajo propone comprender la construcción discursiva del poemario Mapurbe de David Añiñir a partir de la noción de antropofagia sígnica. La presencia del sujeto de la enunciación en un contexto de hibridez cultural posibilita entender la producción estética de Añiñir en el marco de una identidad escindida que, desde la diferencia y la apropiación de elementos culturales ajenos, se posiciona como un discurso innovador en cuanto discurso poético antropófago.

Palabras clave: antropofagia sígnica, Mapurbe, hibridez cultural, discurso poético antropófago.

The present paper proposes to understand the discursive construction in the poetic text Mapurbe of David Añiñir from the anthropophagic signic notion. The presence of the subject of enunciation in a context of cultural hybridism, make possible to understand the aesthetic production of Añiñir within a divided identity, which from the difference and the appropriation of foreign cultural elements is positioned as an innovative discourse in anthropophagic poetic discourse.

Key word: anthropophagic signic, Mapurbe, hybrid cultural, poetic discourse anthropophagic.

\section{INTRODUCCIÓN}

La lectura de Mapurbe venganza a raíz de David Añiñir tal vez sea sólo una excusa para dar cuenta de un diálogo disciplinario que busca resquebrajar imposiciones conceptuales referidas a la conformación de identidades y estructuras culturales esencialistas y territorializadas, sin aceptación del dinamismo simbólico operante desde los procesos de colonización y que actualmente se generan en el contexto de la globalización.

Esta apuesta puede generar contradicciones vislumbradas desde las dinámicas del poder, en cuanto propone una aceptación del intercambio simbólico entre culturas, permite considerar la imposición de la hegemonía cultural sobre las catalogadas minorías culturales en tanto estrategias de dominación; pero ese espacio intersticial 
de flujos puede, también, ser pensado como una frontera de intercambios simbólicos entre unos y otros, transformándose en un espacio de encuentro entre la mismidad y la otredad, un espacio en el cual unos reclaman su diferencia y su aceptación como sujetos insertos en procesos dinámicos de construcción identitaria y cultural abiertos a "una hibridez cultural que mantiene la diferencia sin una jerarquía supuesta o impuesta" (Bhabha, 2002: 20).

En el texto de Añiñir, Mapurbe venganza a raíz, se entretejen los encuentros culturales, signos contaminados que van dibujando y desdibujando la cara de una identidad escindida, hibridación consustancial al ser mismo, con lo cual se derrumban las fronteras axiales de una identidad pensada en/desde los islotes de la fragmentación multicultural.

\section{MAPURBE, UN DISCURSO ANTROPÓFAGO}

En 1928 Oswald de Andrade publicó el Manifiesto antropófago, metatexto de una corriente estética brasileña que dio cuenta de reflexiones cuyo propósito fue repensar las lógicas de dominación o dependencia cultural en Brasil. En su afán por combatir el pensamiento dependentista, Andrade situó el proyecto antropófago como posibilidad de contrarrestar el proyecto deslegitimador de la hegemonía cultural colonizante, asumiendo la deglución de los referentes exógenos; esto se traduce en un canibalismo simbólico que busca resistir la imposición de formas culturales foráneas. Su estrategia de defensa es apropiarse de aquellos elementos que nutren su diferenciación y, por otro lado, acto regurgitorio, expulsar aquellos signos culturales que afectan su propia proyección identitaria. Grüner, al respecto, comprende que el modelo antropófago "digiere" otras culturas "vomitando" lo que no le es útil para aquella construcción diferencial" (Grüner, 2002: 371).

El Movimiento Antropófago levantó un discurso insurgente que tendía a abolir las lógicas unívocas del esencialismo identitario y el binarismo excluyente, optando por un mestizaje cultural en que el acto de deglución simbólica es presentado como performatividad en el discurso para el logro de un proyecto transcultural, pues, como señala Subirats, este movimiento "transforma la dialéctica colonial y poscolonial de sumisiones misiones y discursos subalternos" (Subirats, 2000: 91).

En este sentido, la obra Mapurbe venganza a raíz de David Añiñir se aproxima al proyecto antropófago en tanto escritura del mestizaje, discurso estratégico de la apropiación de referentes culturales del mundo global en imbricación con estrategias de resistencia cultural del pueblo mapuche. Se trata de una discursividad situada en un espacio de enunciación fronterizo, en el cual las identidades se entrecruzan en espirales abiertas, desde lo urbano-marginal a lo mapuche, el Estado nación chileno y la aldea global.

\section{Claves antropófagas}

Browne y Silva proponen pensar lo antropofagia "como fuente de denuncia de una sociedad patriarcal sumida en un discurso occidental que embarga lo ajeno y lo exótico" (Browne y Silva, 2004: 117), siendo la praxis antropófaga la posibilidad de 
transitar a una transculturación operante en el marco de relaciones de mestizaje e hibridación, con lo cual surge un sujeto nómada que se desterritorializa para acceder a un espacio de deglución de signos que lo componen como un "tercero novedoso que es fruto de esta contaminación sígnica, como parte de una semiosis ilimitadaantropófaga" (Browne y Silva, 2004: 123).

En función de lo anterior, los sujetos de la enunciación y del enunciado presentes en el discurso poético de Mapurbe, se someten a los procesos alimenticios de una semiósfera en que los signos se distribuyen heterogéneamente, consumiendo los sistemas significantes de la otredad, pero con una intencionalidad performativa que es capaz de resignificar su nivel semántico en función de un proyecto estético-discursivo de revalidación de la identidad cultural del pueblo mapuche.

Tal situación se expresa en el metatexto poético Mapurbe:

Somos mapuche de hormigón

Debajo del asfalto duerme nuestra madre

Explotada por un cabrón... (Añiñir, 2009: 75).

En estos versos, la referencia a los códigos de configuración urbanística presentan un sujeto que se reconoce como parte de la "mierdópolis" (Añiñir, 2009:75), haciendo alusión al contexto citadino y capitalino de Santiago de Chile. Sin embargo, la posición del sujeto enunciativo expone su relación con el espacio original de procedencia mapuche, el tuwün, sometido y explotado por las lógicas de producción del progreso occidental. Por su parte, el "mapuche de hormigón" es esta nueva identidad emergente en un territorio conflictivo, reconocida como parte de la escisión constitutiva de su ser, pero que no se somete a la anulación de sus matrices culturales.

$\mathrm{Al}$ respecto, es representativo el poema titulado Yeyipun, voz mapuche que hace referencia al rito de invocación de los antepasados y las fuerzas de la naturaleza como instancia de renovación espiritual; este texto posiciona en su discurso no sólo los elementos de la matriz cultural tradicional, sino también a este nuevo sujeto identitario, el mapurbe:

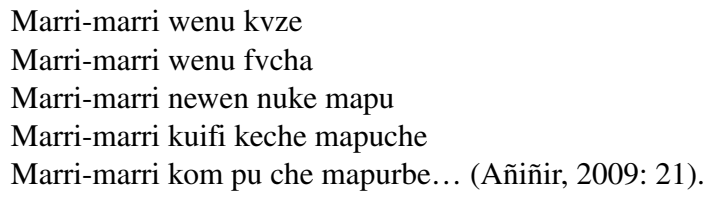

A partir de mecanismos transtextuales (Génette, 1989), en el sentido que el Yayipun se incorpora al "complejo textual" (Carrasco, 1979) poético como discurso proveniente del mundo cultural mapuche ${ }^{1}$, el sujeto textual presenta una nueva configuración del estado del ser mapuche y su ethos cultural; éste no sólo se emplaza en el territorio ancestral, sino también en las redes de un nuevo territorio en el que se resiste a la homogeneización programada por la hegemonía cultural pero que no

\footnotetext{
${ }^{1}$ Sobre el tema del dialogismo textual en la poesía mapuche, Vid. García, Mabel. "Entre-textos: La dimensión dialógica e intercultural del discurso poético mapuche". Revista Chilena de Literatura $\mathrm{N}^{\circ} 72$, abril. 2008, pp. 29-70.
} 
se puede rechazar en su totalidad; al ser heredero de los elementos culturales provenientes del mundo occidental, Añiñir es capaz de configurar un espacio discursivo en que la escritura sirve como medio para instalar formas discursivas propias de la oralidad mapuche; de este modo se posibilita una instancia de encuentro entre matrices culturales diferenciadas y se da cuenta de una "actitud de denuncia y la posición de resistencia cultural ante los elementos culturales homogeneizantes" (García, 2008: 51). En el poema, esta situación se presenta en función de la actitud apelativa -propia del Yeyipun-dirigida a los ancestros, cuyo propósito es requerir ayuda para el cuidado de los jóvenes que habitan la "warría mapu" y por los presos políticos mapuches: "Kelluaiñ tufachi weche keche mapuche warría muley / Kelluaiñ ta presos políticos mapuches..." (Añiñir, 2009: 21).

Esta nueva realidad del pueblo mapuche se presenta gracias a una poética que inscribe los sucesos históricos, políticos y culturales que se han llevado a cabo a partir del contacto cultural entre el mundo mapuche y el occidental; claro que en el caso de Mapurbe, estos son actualizados en un constante devenir al presente, logrando de este modo demostrar aspectos de una identidad que se ha resignificado continuamente y que adquiere matices inesperados en la era actual.

\section{Sujetos Antropófagos}

Para poder sustentar la última idea formulada en el punto anterior, recurriré al poema "Lautaro", texto que explicita referentes de una cultura subsumida en las tecnologías del mundo virtual.

La relación formulada entre el personaje histórico Lautaro y el mundo virtual da cuenta de una posición híbrida del sujeto postmoderno, situado en un panorama social y cultural en que la tradición se confronta con lo moderno. En este sentido, el texto puede ser leído desde la problemática de la modernidad en el contexto latinoamericano, teniendo como base a García Canclini (1995) en relación al hibridismo que sufren las culturas latinoamericanas en la era de las simbiosis y mutaciones simbólicas que experimenta el continente.

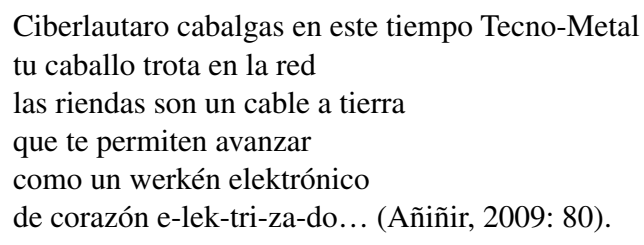

El fragmento citado nos remite al reconocimiento de una memoria histórica que instala en el presente del "tiempo Tecno-Metal" al héroe mapuche. Pero, éste se presenta desmitificado en comparación con su construcción histórica. Su existencia temporal y espacial en la era de la virtualidad desdibuja el perfil épico tradicional de sus hazañas, para ahora cabalgar por la red como un mapurbe más, por el espacio de flujos donde los significantes se trasladan rizomáticamente por la derogación de la linealidad que promueve el hipertexto (Landow, 2009); ello no apunta a la anulación de sentidos, por el contrario, articula una semiosis antropófaga en que los referentes 
tradicionales de la cultura mapuche se expresan en este Ciberlautaro, "werkén elektrónico", que transita como portador de un mensaje desde la clandestinidad, espacio marginal asumido por "Neolautaro" para provocar la concientización de la resistencia en sus internautas:

\author{
Lautaro \\ Montado sobre este peludo sistema \\ Cabalgas en la noche \\ Pirateando sin miedo el miedo \\ Chateando cerebros y conciencias \\ Pasando piola en la red... (Añiñir, 2009: 80).
}

En palabras de Barros, este texto "resemantiza el espacio cibernético como un nuevo lugar de la resistencia mapuche o como la continuación de la guerra de Arauco, que -como toda batalla- es vivida de modo problemático por Ciberlautaro" (Barros, 2008: 39).

La lucha por la resistencia cultural a la que hace mención Barros está perfilada desde un nuevo modo de ser mapuche, cuyo ethos cultural se alimenta de los trazados simbólicos que desde la aldea global se diseñan, articulando procesos de hibridez propios de un mundo postmoderno en que la identidad es desafiada a rechazar los paradigmas estabilizadores para dar paso a una identidad de lo múltiple (Subercaseaux, 2002). Tal es el caso de Lautaro, sujeto antropófago y transeúnte del espacio virtual como un mapurbe que entra y sale de lo local y lo global.

\title{
5. Nomadismo en Mapurbe
}

Siguiendo a García Canclini (1995), afirmo que en la producción artística de nuestro continente se evidencia la complejidad de la construcción cultural de la cual somos hereditarios, siendo el arte un producto simbólico que actúa como correlato de los fenómenos extratextuales. En su propuesta, éste establece que Latinoamérica se dinamiza entre la modernidad y la postmodernidad, entendiendo la primera como conglomeración de lo tradicional con las innovaciones diseñadas a partir del contacto cultural, económico, comunicacional que se ha sostenido a lo largo de la historia con el resto del mundo. Estas innovaciones fueron detonadas por la articulación a la que se expuso el continente en relación al influjo de referentes exógenos que emergen desde la conquista, se actualizan en el siglo XIX por el afán independentista de la época y adquieren mayor fuerza desde el siglo XX hasta nuestros días; esto ha sucedido en especial por la inserción en las lógicas del capitalismo y la globalización que promueven estrategias de alteración de lo establecido sin descuidar los referentes que legitiman su autonomía (García Canclini, 1995). En el caso de la postmodernidad, García Canclini la establece "no como una etapa o tendencia que remplazaría el mundo moderno, sino como una manera de problematizar los vínculos equívocos que éste armó con las tradiciones que quiso excluir o superar para constituirse" (García Canclini 1995: 23); el pensamiento postmoderno es aquel que posibilita revisar la simplificación de la propuesta moderna en cuanto separación total de las culturas y naciones, generando "universos autosuficientes" (id. 1995:18) y apostando por un pensamiento más flexible 
que sea capaz de "abarcar las interacciones e integraciones entre los niveles, géneros y formas de la sensibilidad colectiva" (id.1995: 23).

En este plano, el poemario Mapurbe da cuenta de la interacción e integración de diversas realidades en que este nuevo ser mapuche habita. La capacidad de Añiñir de hacer converger estadios sociales marginales, referencias culturales propias del mundo mapuche, el apogeo de los influjos simbólicos y materiales del mundo global, todo a modo de bricolaje, explicita una estética que desvanece los moldes inquebrantables y el rechazo taxativo de lo tradicional por imposibilitar la innovación, optando por una discursividad estético-social amparada en la reivindicación y resistencia cultural a través de actos de entrada y salida de los márgenes creados por el mundo actual.

Mapurbe, en este transitar por lo heterogéneo, nos presenta un nomadismo identitario como "máquina de guerra" (Deleuze y Guattari, 2000), en el sentido de que su desplazamiento apunta a una liberación rizomática en contra de los estancamientos que tienden a perpetuar lo unívoco, la imposición, la trinchera caduca situada por las élites. Esta obra es un claro ejemplo de la constante desterritorialización del sujeto en tanto entidad movilizante de sentidos que se despliegan por una cartografía del afuera y del adentro, espacio intermedio en donde se recrea en un devenir perenne lo que somos y lo que nos falta por ser.

En el mapuchema ${ }^{2}$ Pewkayeal podrido dinero, se reconoce este nomadismo:

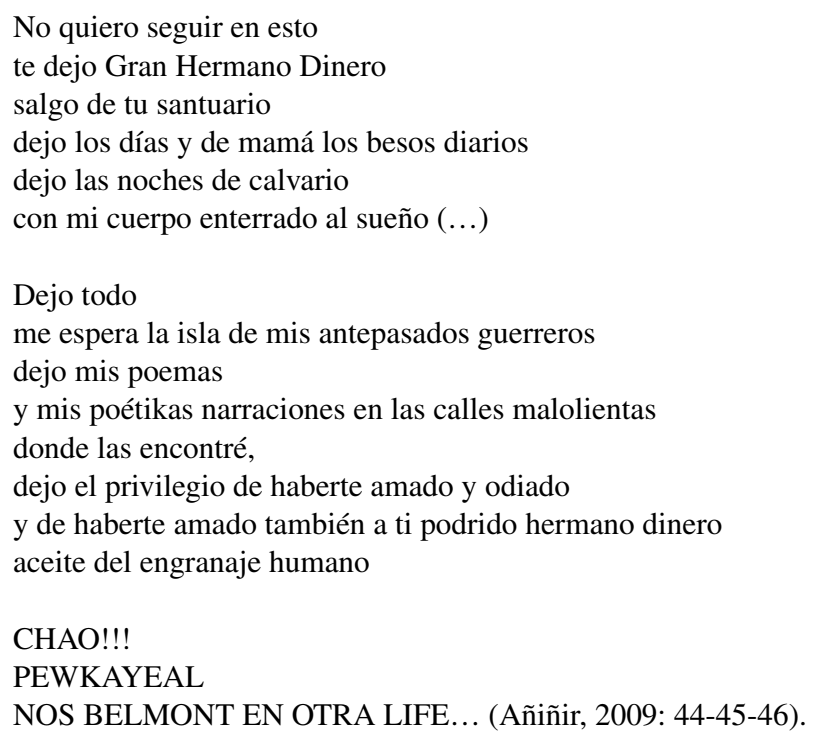

Los versos citados permiten reconocer a un sujeto nómade que es capaz de generar recorridos de fuga frente al estancamiento que promueve la estadía sedentaria junto al "Gran Hermano Dinero", concepto con el cual se evoca la mercantilización de la realidad, "Aparato de Estado", siguiendo a Deleuze y Guattari (2000) ${ }^{3}$.

\footnotetext{
2 Término con el cual Añiñir nombra sus poemas.

${ }^{3}$ En contraposición al Estado y sus aparatos de control, instrumentos impositivos y reguladores de modelos estables de reproducción hegemónica, las armas de guerra del nómade son sus estrategias de transgresión,
} 
Desde su posición nómade, el sujeto textual se desplaza a los territorios ancestrales, búsqueda rizomática por la integración del sentido originario jamás resquebrajado, pues el rizoma permanece alerta a las posibilidades de interconexión con distintos puntos de encuentro, en este caso, la búsqueda por asumir el propio destino, el filew, para converger con los antepasados. Además, en esta identidad de lo múltiple, los tres últimos versos citados son organizados a partir del manejo de una variabilidad lingüística fronteriza que entremezcla el castellano, el mapudungun y aspectos diafásicos propios de la creatividad de los sectores marginales, generando una alternancia de códigos como performance lingüística antropófaga.

El nomadismo en Mapurbe, coincide con la revisión que Browne y Silva (2004) realizan sobre el concepto de nómada.

Para los autores:

El nómada puede considerarse como desterritorializado porque a diferencia del migrante, la reterritorialización no la hace posteriormente, ni en otra cosa como en el caso del sedentario. La desterritorialización para el nómada constituye su relación con la tierra, por ello se reterritorializa en la propia desterritorialización (Browne y Silva, 2004: 21).

El mapurbe como sujeto nómada se desterritorializa en un devenir constante, fluctuación existencial-territorial en la cual se resemantiza por los múltiples constructos semióticos que le otorgan una identidad escindida, acceso a lo diverso desde una actitud consciente en la que el dilema shakespeareano "ser o no ser" se vuelve vacuo, acá es ser seres, resultado de la fluctuación por los engranajes múltiples de la identidad.

\section{MAPurbe DeSde el Pensamiento Mestizo}

Rodrigo Alsina (2000), siguiendo los postulados de Leplantaine y Nouss respecto al pensamiento mestizo (1997), propone pensar la identidad cultural en un marco intercultural, aseverando "que lo intercultural es constitutivo de lo cultural. Por consiguiente, se trata de descubrir el origen intercultural de nuestra cultura, que es una cultura mestiza" (Rodrigo, 2000: 56).

El pensamiento mestizo, según Rodrigo, posibilita asumir la identidad desde la pluralidad, las diferencias y las similitudes que alberga cada cultura, concepción asociada al paradigma relacional postmoderno, el cual, según el autor "redefine lo universal y lo particular no como antítesis sino a partir de sus relaciones recíprocas"

de liberación frente al estancamiento de las jerarquías. (Deleuze y Guattari, 2000). Si bien los aparatos de Estado pueden apropiarse de las máquinas de guerra - tal como lo señalan los autores en el Tratado de Nomadología - y adscribirlas a sus deliberaciones, las armas de guerra buscarán trazos de huida, capacidad de invención para no subordinarse.

En este marco explicativo, la voz poética de Añiñir es máquina de guerra, mecanismo de desplazamiento por la liberación, fuerza subversiva que apuesta por el encuentro con la diferencia.

Browne, al respecto, establece que: "La máquina se desliga del Estado y lo deja de lado ya que éste, en su fuero interno, no posee máquina de guerra. Se apodera de ella cuando la necesita, en forma de institución militar y, por lo mismo, siempre le plantea problemas. La máquina de guerra invita a una indisciplina del guerrero, a un cuestionamiento de las jerarquías (...) a una transgresión que impide la conformación y estabilidad del Estado" (Browne, 2009: 130). 
(Rodrigo, 2000:58). A su vez, este modo de entender la identidad cultural genera una lucha frente al multiculturalismo, concepto que encierra "el discurso esencialista de la pureza autentificadora" (Rodrigo, 2000: 62).

Se acude a esta forma de pensamiento concibiendo el poemario Mapurbe como producto simbólico cultural asociado al pensamiento mestizo, complementando la idea de la antropofagia sígnica/cultural establecida por Browne y Silva (2004). Sin embargo, es necesario develar que el mestizaje, en el caso de Mapurbe, se configura desde una dinámica compleja, que si bien puede proyectar la relación de los contrarios, éstos son presentados desde un ethos cultural en constante tensión respecto a los referentes históricos que han desplazado al mapuche a espacios de exclusión social y cultural.

Caso particular para dar cuenta de esta categoría del mestizaje es el mapuchema María Juana la Mapunky de la Pintana ${ }^{4}$. En este texto, el hablante lírico nos presenta a un tipo de sujeto híbrido, situado en la marginalidad citadina de Santiago de Chile. La Mapunky, acudiendo al glosario del texto, es la "mapuche punx, especie natural de los suburbios" (Añiñir, 2009: 95).

La Mapunky habita en la Pintana, espacio catalogado como urbano-marginal, etiqueta que es impuesta según las lógicas fragmentarias y estratificantes que la "Ciudad Fractal" promueve, siguiendo la lectura de Edward Soja (2001) para quien este tipo de ciudad se conforma por la polarización y distribución desigual de los capitales económicos; de ellos el mapurbe es hereditario, pues los procesos migratorios del mapuche a la ciudad se han caracterizado por su emplazamiento en este tipo de sectores sociales, nuevas reducciones territoriales en las cuales son localizados, lo que en la dinámica de la aldea global sería un proceso de exclusión al estar situados en la marginalidad.

No obstante, la Mapunky es capaz de desplazarse por medio del consumo simbólico a referentes provenientes del mundo europeo, en específico el movimiento punk. A partir de este mecanismo de "apropiación cultural" (Bonfil,1988), el sujeto se rediseña identitariamente, asumiendo un nomadismo que le permite acceder a un nuevo ethos cultural de lucha y resistencia: en los mecanismos de apropiación los elementos culturales ajenos pasan a ser propios, adquiriendo una autolegitimación respecto a su diferenciación.

\footnotetext{
${ }^{4}$ Gastarás el dinero / del antiquísimo vinagre burgués / Para recuperar lo que de él no es./ Volarás sobre la nube de plata/ arrojarás bolas y lanzas de nieve/ hacia sus grandes fogatas / Eres tierra y barro / mapuche sangre roja como la del apuñalado / Mapuche en F. M. (o sea, Fuera del Mundo) / eres la mapuche "girl" de marca no registrada / de la esquina fría y solitaria apegada a ese vicio, / tu piel oscura es la red de SuperHiperArchi venas / que bullen a borbotones sobre una venganza que condena. / Las mentiras acuchillaron los papeles / y se infectaron las heridas de la historia. / Un tibio viento de cementerio te refresca / mientras de la nube de plata estallan explosiones eléktricas llueven indios en lanza / Lluvia negra color venganza./Oscura negrura of Mapulandìa street / si, es triste no tener tierra / loca del barrio La Pintana / el imperio se apodera de tu cama / Mapuchita kumey kuri Malén / vomitas a la tifa que el paco Lucia / y el sistema que en el calabozo crucificó tu vida / In the name of father / of the son / and the saint spirit / AMÉN / y no estas ni ahí con ÉL / Lolindia, un xenofóbico Paco de la Santa Orden / engrilla tus pies para siempre / sin embargo, / tus pewmas conducen tus pasos disidentes / Mapulinda, las estrellas de la tierra de arriba son tus liendres / los ríos, tu pelo negro de déltikas corrientes / kumey kuri Malèn / loca mapunky pos-tierra / entera chora y peluda / pelando cables pa` alterar la intoxicada neuro / Mapurbe; / la libertad no vive en una estatua allá en Nueva York / la libertad vive en tu interior / circulando en chispa de sangre / y pisoteada por tus pies / amuley wixage anay / Mapunky kumey kuri Malèn / LA AZCURRIA ES GRATIS.
} 
Este proceso de mestizaje permite la consolidación de un proyecto identitario que desenmascara su naturaleza de esencialismo autentificador, para acceder a un territorio de contaminación sígnica que le posibilita desterritorializarse y avanzar en el diseño de una identidad distinta pero que no olvida el estado de procedencia, "tus pewmas conducen tus pasos disidentes" (Añiñir, 2009: 33). Sin embargo, no se niega a la antropofagia cultural, al pensamiento mestizo como estrategia para resistir: "Eres tierra y barro / mapuche sangre roja como la del apuñalado / Mapuche en F. M. (o sea, Fuera del Mundo)" (Añiñir, 2009: 32).

Por su parte, el consumo de la cultura punk es el aliciente para disentir frente a la exclusión, actualización ideológica-identitaria del mapurbe a modo de asumirse desde una condición contrahegemónica frente a los determinismos que deslegitiman su estar en el mundo.

Es interesante en este punto aproximarse a los estudios culturales referidos a la conformación de identidades juveniles, entendiendo que la Mapunky es una joven que deviene en identidad híbrida como resultado de su emplazamiento en dos redes culturales, lo social y lo étnico.

La Mapunky sería parte de lo que Feixa conceptualiza como Culturas Parentales, refiriéndose a:

las grandes redes culturales, definidas fundamentalmente por identidades étnicas y de clase, en el seno de las cuales se desarrollan las culturas juveniles, que constituyen subconjuntos. Refieren las normas de conducta y valores vigentes en el medio social de origen de los jóvenes (Feixa, 1999: 86).

En consideración de lo anterior, la Mapunky es el resultado del entrecruzamiento de su posición social marginal y su condición étnica mapuche, de la cual emerge su categoría de mapurbe. A esto se debe agregar el condicionante punk, que le atribuye, siguiendo a Feixa, su posición contracultural, en la medida que la Mapunky se reconoce como parte de la lucha por resistir a la aculturación, la invisibilización, el abuso y la marginalidad en el contexto histórico de la urbe contemporánea:

Lolindia, un xenofóbico Paco de la Santa Orden

engrilla tus pies para siempre

sin embargo,

tus pewmas conducen tus pasos disidentes

Mapulinda, las estrellas de la tierra de arriba son tus liendres

los ríos, tu pelo negro de déltikas corrientes

kumey kuri Malèn

loca mapunky pos-tierra

entera chora y peluda

pelando cables pa`alterar la intoxicada neuro ... (Añiñir, 2009: 33-34).

\section{REFLEXIONES PARA EL CIERRE}

En el texto de Añiñir, la antropofagia sígnica se impone como categoría de análisis articulatoria de una semiosis que se va nutriendo a modo de excusa para sustentar 
lecturas de realidad que apuestan por la transgresión de miradas reduccionistas que abogan por el distanciamiento multiculturalista.

El territorio escritural que nos presenta Añiñir ha sido leído desde posicionamientos epistemológicos adscritos a un indisciplinamiento frente al saber-poder, a propósito de las construcciones hegemónicas que se han configurado respecto a la identidad de los excluidos y subordinados; para ello se ha asumido que la antropofagia, según los postulados de Browne y Silva, se manifiesta como estrategia para la hibridación desde la diferencia, acción subalterna al control de lo propio y al deseo por la alteridad, ejercicio consciente que se alimenta de los espacios intersticiales, sin dar oportunidad a la enajenación pues es desafiante ante el poder.

La antropofagia es revolucionaria en Añiñir, su discursividad presentada como acto deglutorio de simbólicas heterogéneas le permite atravesar las fronteras de la mismidad y la alteridad configurando una semiósfera transcultural que le sirve como instancia de lucha y resistencia. La poética de Añiñir devela un espacio intermedio en que surgen nuevas miradas y actitudes para devenir en un otro en constante configuración identitaria, sin desarraigarse de las matrices de lo urbano; de ahí su ensamblaje conceptual y su apuesta por una estética mapuche-urbana.

\section{Obras CITADAS}

\section{Fuente primaria:}

Añiñir, David. 2009. Mapurbe, Venganza a Raíz. Santiago: Pehüen.

\section{Fuentes secundarias:}

Andrade, Oswald de. 1928. "Manifiesto antropófago", Revista de Antropofagia, 1: 3-7.

Barros, María. 2009. "La(s) identidad(es) Mapuche(s) desde la ciudad global en Mapurbe venganza a raíz de David Añiñir. Revista Chilena de Literatura 75: 29-46.

Bhabha, Homi. 2002. El lugar de la cultura. Buenos Aires: Manantial.

Browne, Rodrigo. 2009. De la comunicación disciplinaria a los controles de la comunicación. La antropofagia como transgresión cultural. Sevilla: Alfar.

— y Víctor Silva. 2004. Escrituras híbridas y rizomáticas. Pasajes intersticiales, pensamiento del entre, cultura y comunicación. Sevilla: Arcibel.

Bonfil, Guillermo. 1988. "La teoría del control cultural en el estudio de procesos étnicos" en Papeles de la Casa Chata, año 2. № 3: 23-43.

Carrasco, Iván. 1979. "Dos discursos complementarios: las dedicatorias y las notas". Estudios Filológicos 14: 129-137.

Deleuze, Gilles y Felix Guattari. 2000. Mil mesetas. Capitalismo y Esquizofrenia. Valencia: Pretexto.

Feixa, Carles. 1999. De Jóvenes, Bandas y Tribus. Antropología de la Juventud. Barcelona: Ariel S.A.

García, Mabel. 2008. "Entre-textos: La dimensión dialógica e intercultural del discurso poético mapuche." Revista Chilena de Literatura 72: 29-70.

García Canclini, Néstor. 1995. Culturas Híbridas. Estrategias para entrar y salir de la modernidad. Buenos Aires: Sudamericana.

Génette, Gérard. 1989. Palimpsestos. La literatura en segundo grado. Madrid: Taurus. 
Grüner, Eduardo. 2002. El fin de las pequeñas historias. De los estudios culturales al retorno (imposible) de lo trágico. Buenos Aires: Paidós.

Landow, George. 2009. Hipertexto 3.0. Teoría crítica y nuevos medios en la era de la globalización. Barcelona: Paidós.

Leplantine, Françoise. y Alexis Nouss. 1997. Le Métissage. París: Flammarion.

Rodrigo Alsina, Miquel. 2000. La comunicación intercultural. Barcelona: Anthropos.

Soja, Edward. 2001. Postme- tropolis. Critical Studies of Cities and Regions. Oxford: Blackwell.

Subercaseaux, Bernardo. 2002. Nación y cultura en América Latina. Diversidad cultural y globalización. Santiago: LOM.

Subirats, Eduardo. 2000. "Antropofagia contra globalización o el Paraíso en América Latina". Quimera 193-194: 88-91. 
